\title{
Surface ECG interatrial block-guided treatment for stroke prevention: rationale for an attractive hypothesis
}

\author{
Antoni Bayés de Luna ${ }^{1}$, Manuel Martínez-Sellés ${ }^{2,6^{*}}$ D, Antoni Bayés-Genís ${ }^{3}$, Roberto Elosua ${ }^{4}$ and Adrian Baranchuk ${ }^{5}$
}

\begin{abstract}
Atrial fibrillation (AF) is the most common sustained arrhythmia and is associated with stroke, cognitive impairment, and cardiovascular death. Some predisposing factors - as aging, diabetes, hypertension - induce and maintain electrophysiological and ultrastructural remodeling that usually includes fibrosis. Interatrial conduction disturbances play a crucial role in the initiation of atrial fibrosis and in its associated complications. The diagnosis of interatrial blocks (IABs) is easy to perform using the surface ECG. IAB is classified as partial when the P wave duration is $\geq 120 \mathrm{~ms}$, and advanced if the $\mathrm{P}$ wave also presents a biphasic pattern in II, III and aVF. IAB is very frequent in the elderly and, particularly in the case of the advanced type, is associated with AF, AF recurrences, stroke, and dementia. The anticoagulation in elderly patients at high risk of AF without documented arrhythmias is an open issue but recent data suggest that it might have a role, particularly in elderly patients with structural heart disease, high $\mathrm{CHA}_{2} \mathrm{DS}_{2} \mathrm{VASc}$ (Congestive heart failure/left ventricular dysfunction, Hypertension, Age $\geq 75$ [doubled], Diabetes, Stroke [doubled] - Vascular disease, Age 65-74, and Sex category [female]), and advanced IAB. In this debate, we discuss the association of surface ECG IAB, a marker of atrial fibrosis, with $\mathrm{AF}$ and stroke. We also present the rationale that justifies further studies regarding anticoagulation in some of these patients.
\end{abstract}

Keywords: Interatrial block, Atrial fibrillation, Stroke, Risk

\section{Background}

Atrial fibrillation (AF) is the most common sustained arrhythmia, and is currently considered a worldwide epidemic. AF usually occurs in patients with "atria at risk", atria that have specific characteristics, including slow conduction. Fibrosis plays a key role in this process, especially in patients that present with AF in the context of advanced heart disease and aging [1]. Fibrosis usually is the consequence of a chain of events that are triggered by abnormal activation of the left atrium due to interatrial blocks (IABs) [2]. As recognized recently, AF is not necessary the main cause of stroke but rather is another important risk factor for stroke [3]. Interatrial conduction disturbances play crucial roles in the initiation of atrial fibrosis development and its associated complications.

\footnotetext{
* Correspondence: mmselles@secardiologia.es

${ }^{2}$ Hospital General Universitario Gregorio Marañón. CIBERCV, Universidad

Complutense, Universidad Europea, Madrid, Spain

${ }^{6}$ Servicio de Cardiología, Hospital General Universitario Gregorio Marañón,

Calle Dr. Esquerdo 46, 28007 Madrid, Spain

Full list of author information is available at the end of the article
}

\section{Interatrial block is an independent factor associated with atrial fibrillation, stroke, and cognitive impairment}

$\mathrm{IAB}$ is the most common and well-known block at the atrial level. IABs are classified as partial IABs (P-IABs) that are observed on the surface ECG as a positive $P$ wave $\geq 120 \mathrm{~ms}$, or as advanced IABs (A-IABs) manifested as a $P$ wave $\geq 120$ ms plus biphasic $( \pm)$ morphology in leads II, III, and aVF (Fig. 1). In 2012, a consensus document was published that confirmed these criteria and stated that IAB was a separate entity from left atrial enlargement [4]. IAB is frequently found in the elderly, with a prevalence of $8 \%$ in septuagenarians and $25 \%$ in centenarians [5]. The prevalence is also high in patients with structural heart disease.

The biopsy tissue of patients with lone AF show abnormal atrial histology, as do the tissues of patients with paroxysmal AF [6]. Patients with lone AF present with different degrees of interatrial conduction disturbances and, compared with controls, present with more delayed 


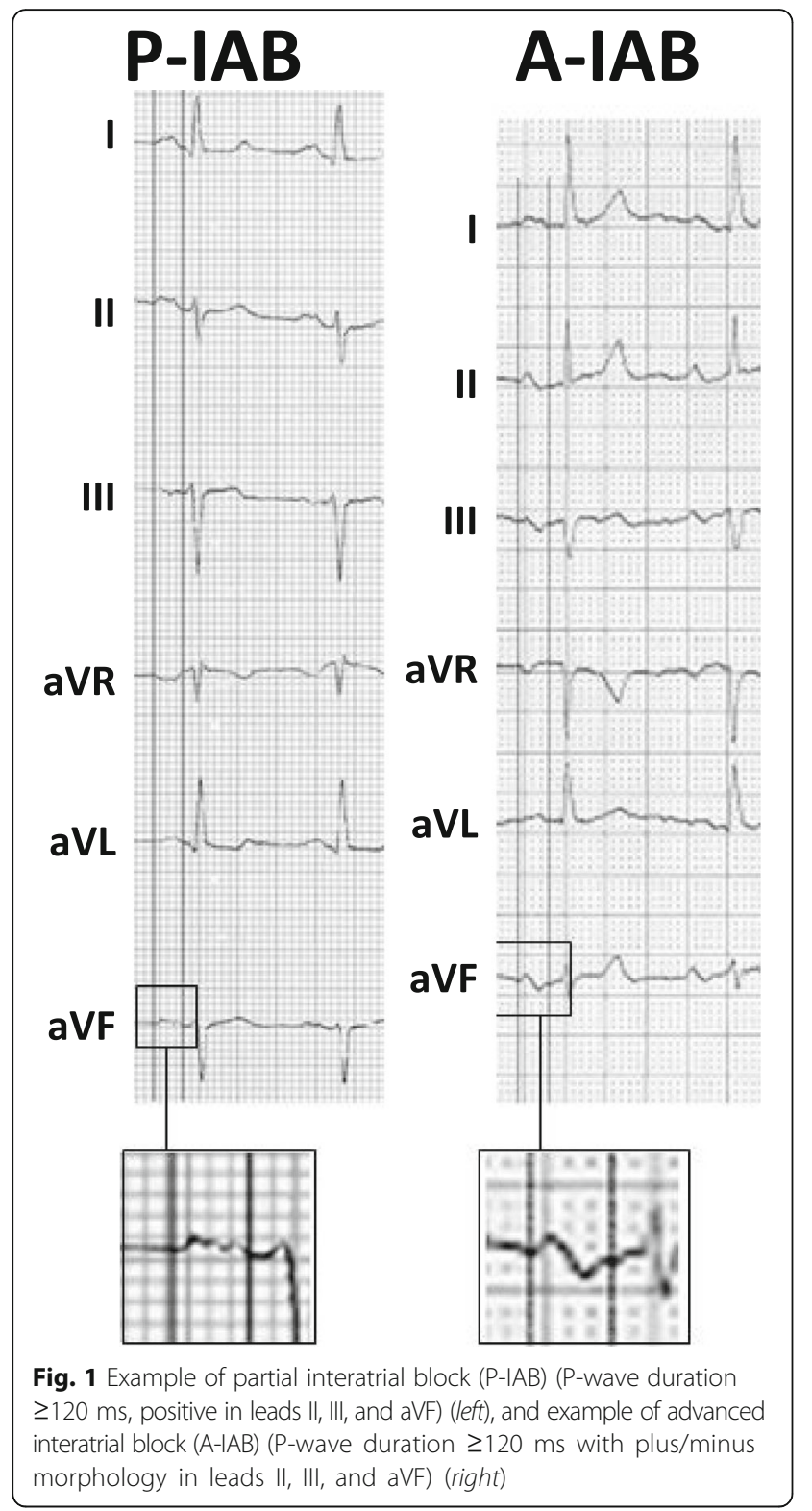

and slower intra-atrial conduction and shorter effective refractory periods [7]. Patients with A-IABs have a higher incidence of AF than those with P-IABs [8], an association that is termed Bayes' syndrome [9]. This association of IAB and AF has been confirmed in many studies performed in different settings, mainly by groups led by Spodick and Baranchuk [10, 11]. In a large cohort of unselected individuals, the incidence of AF was higher in the presence of A-IAB [12].

The association of IABs and embolic stroke has been demonstrated in hospitalized patients [13], in the general population [14], and in patients with high CHA2DS2VASc scores [15]. Furthermore, Martinez-Sellés et al. [5] found that in centenarians, the presence of A-IAB is associated with previous stroke and cognitive impairment.

\section{How to measure atrial fibrosis?}

Atrium fibrosis is a common feature in patients with AF, the causality of this association is not yet clarified but the association seems to be bidirectional: fibrosis increases the risk of AF that in turn induces fibrosis. In post-mortem samples, the extent of fibrosis and fatty tissue in the zones of the crista terminalis, Bachmann's bundle region, and superior pulmonary veins is more extensive in patients with longer P-waves $(P>160 \mathrm{~ms})$ [4]. Contrast-enhanced cardiac magnetic resonance (CMR) imaging may be the optimal non-invasive method for evaluating and quantifying left atrium fibrosis [16]. The amount of atrial fibrosis and the atrial strain rate, as detected by new echocardiographic techniques, correlates well with the likelihood of AF recurrence [16]. CMR imaging shows a higher mean value of fibrosis in patients with persistent vs. paroxysmal AF, yet the extent of fibrosis is not always related to the phenotype of AF. Large areas of fibrosis have been detected in some paroxysmal AF cases, while only mild fibrosis has been found in some persistent AF cases. Thus, the causal relation between AF duration and the extent of fibrosis requires further insight [16]. In patients with lone AF, the atrial substrate may progress despite successful AF ablation, indicating an independent progressive course in some cases of idiopathic atrial fibrotic cardiomyopathy.

It would be desirable to perform CMR or to use new echocardiographic techniques to determine the burden of atrial fibrosis to the full spectrum of patients at risk. In their absence, we recommend a careful analysis of the P-wave on surface ECG, which emerges as a cheap, easy and valuable surrogate of the atrial fibrotic process. Indeed, patients with A-IAB present with low atrial mobility due to the large amount of fibrosis and with reduced strain by speckle-tracking echocardiography [17]. This is important as left atrial deformation measured with speckle tracking echocardiography has been associated with AF recurrence [18]. Moreover, extensive atrial fibrosis assessed by late gadolinium enhancement CMR has been associated with advanced IAB [19].

\section{Should anticoagulation be used in some patients with advanced interatrial block before they have documented atrial fibrillation?}

$\mathrm{A}-\mathrm{IAB}$ is an independent risk factor for AF and embolic stroke, and there is evidence that this risk increases in the presence of a high CHA2DS2-VASc score and advanced age. Surface ECG IAB should be considered in the risk stratification of patients in sinus rhythm that are at high risk of stroke, even if they have no documented AF $[20,21]$. Also, the bleeding risk of elderly patients that receive anticoagulation should be taken into account. HAS-BLED score for major bleeding is very useful for this risk assessment, although, in the case of AF 
the net clinical benefit of anticoagulation seems to exist in almost all patients, as the risk of ischemic stroke without anticoagulant treatment is higher than the risk of intracranial bleeding with anticoagulant treatment [22]. However, before anticoagulation therapy is indicated in patients with no documented AF, two steps should be taken. The first step is to perform a prospective international registry to confirm that IAB is associated with a high risk of AF and stroke in the elderly population with heart disease [22]. After showing the magnitude of this association, the second step is to perform a randomized control trial to test the benefits of anticoagulation in patients with heart disease, sinus rhythm, and A-IAB [23], probably adding as inclusion criteria other factor related with AF and stroke as advanced age [24] and atrial ectopy [25]. Our hypothesis also opens the door to other drugs, for instance as the renin-angiotensin-aldosterone system inhibition might have a role in the reduction of the risk of developing new onset AF [26], these medications might improve prognosis of patients with advanced IAB.

Finally, we would like to clarify that our hypothesis is based on data of patients without rheumatic heart disease. However, patients with IAB and rheumatic disease probably have an even higher risk of stroke as the burden of atrial fibrosis is noteworthy in patients with AF and rheumatic heart disease [27].

\section{Conclusions}

The presence of IAB, which is easily identifiable on surface ECG, may be a marker of a chain of events that leads to AF and stroke. IAB is common in the elderly and may be considered as a surrogate marker of atrial fibrosis. Patients with heart disease and IAB might benefit from early anticoagulation even without documented AF. This hypothesis needs to be confirmed with larger studies.

\section{Abbreviations \\ - $\mathrm{CHA}_{2} \mathrm{DS}_{2}$ VASc: Congestive heart failure/left ventricular dysfunction, Hypertension, Age $\geq 75$ [doubled], Diabetes, Stroke [doubled] - Vascular disease, Age 65-74, and Sex category [female]; AF: Atrial fibrillation; CMR: Cardiac magnetic resonance; HAS-BLED: Hypertension, Abnormal renal and liver function, Stroke, Bleeding, Labile INRs, Elderly ( $\geq 65$ years), Drugs or alcohol; IAB: Interatrial block}

\section{Acknowledgements}

Not applicable.

Funding

Not applicable.

\section{Availability of data and materials}

Not applicable.

\section{Authors' contributions}

$A B L$ and MMS idea and draft of the first version; $A B G, R E$ and $A B$ were major contributors in writing the manuscript. All authors read and approved the final manuscript.
Ethics approval and consent to participate

Not applicable.

\section{Consent for publication}

Not applicable.

\section{Competing interests}

The authors declare that they have no competing interests.

\section{Publisher's Note}

Springer Nature remains neutral with regard to jurisdictional claims in published maps and institutional affiliations.

\section{Author details}

${ }^{1}$ Fundació Investigació Cardiovascular, ICCC, Hospital de Sant Pau, Barcelona, Spain. ${ }^{2}$ Hospital General Universitario Gregorio Marañón. CIBERCV, Universidad Complutense, Universidad Europea, Madrid, Spain. ${ }^{3}$ Hospital Universitari Germans Trias i Pujol, UAB, Barcelona, Spain. ${ }^{4}$ Hospital del Mar Medical Research Institute, Barcelona, Spain. ${ }^{5}$ Queen's University, Kingston, ON, Canada. 'Servicio de Cardiología, Hospital General Universitario Gregorio Marañón, Calle Dr. Esquerdo 46, 28007 Madrid, Spain.

Received: 14 June 2017 Accepted: 27 July 2017

Published online: 31 July 2017

\section{References}

1. Kottkamp H. Human atrial fibrillation substrate: towards a specific fibrotic atrial cardiomyopathy. Eur Heart J. 2013;34:2731-8.

2. Goyal S, Spodick D. Electromechanical dysfunction of the left atrium associated with interatrial block. Am Heart J. 2001;142:823-7.

3. Glotzer TV, Daoud EG, Wyse DG, et al. The relationship between daily atrial tachyarrhythmia burden from implantable device diagnostics and stroke risk. The TRENDS Study Circ Arrhythm Electrophysiol. 2009;2:474-80.

4. Bayés de Luna A, Platonov P, Cosio FG, et al. Interatrial blocks. A separate entity from left atrial enlargement: a consensus report. J Electrocardiol. 2012;45:445-51.

5. Martínez-Sellés M, Massó-van Roessel A, Álvarez-Garcia J, (The investigators of the cardiac and clinical characterization of centenarians (4C) registry), et al. Interatrial block and atrial arrhythmias in centenarians: prevalence, associations, and clinical implications. Heart Rhythm. 2016;13:645-51.

6. Platonov PG, Mitrofanova LB, Orshanskaya V, Ho SY. Structural abnormalities in atrial walls are associated with presence and persistency of atrial fibrillation but not with age. J Am Coll Cardiol. 2011;58:2225-32.

7. Cosio FG, Palacios J, Vidal JM. Electrophysiologic studies in atrial fibrillation. Slow conduction of premature impulses: a possible manifestation of the background for reentry. Am J Cardiol. 1983;51:122-30.

8. Bayés de Luna A, Cladellas M, Oter R, et al. Interatrial conduction block and retrograde activation of the left atrium and paroxysmal supraventricular tachyarrhythmia. Eur Heart J. 1988:9:1112-8.

9. Baranchuk A, Bayes-Genis A. Bayés' Syndrome. Rev Esp Cardiol. 2016;69:439.

10. Gul EE, Pal R, Caldwell J, et al. Interatrial block and interatrial septal thickness in patients with paroxysmal atrial fibrillation undergoing catheter ablation: Long-term follow-up study. Ann Noninvasive Electrocardiol. 2017;22(4). doi:10.1111/anec.12428.

11. Spodick DH, Ariyarajah V. Interatrial block: the pandemic remains poorly perceived. Pacing Clin Electrophysiol. 2009;32:667-72.

12. O'Neal WT, Zhang $Z M$, Loehr $L R$, et al. Electrocardiographic advanced interatrial block and atrial fibrillation risk in the general population. Am J Cardiol. 2016; 117:1755-9.

13. Ariyarajah V, Puri P, Apiyasawat S, Spodick DH. Interatrial block: a novel risk factor for embolic stroke? Ann Noninv Electrocardiol. 2007;12:15-20.

14. O'Neal WT, Kamel $\mathrm{H}$, Zhang ZM, et al. Advanced interatrial block and ischemic stroke. Neurology. 2016;87:352-6.

15. Wu JT, Wang SL, Chu YJ, et al. CHADS2 and CHA2DS2-VASc scores predict the risk of ischemic stroke outcome in patients with interatrial block without atrial fibrillation. J Atheroscler Thromb. 2017:24:176-84.

16. Longobardo L, Todaro MC, Zito C, et al. Role of imaging in assessment of atrial fibrosis in patients with atrial fibrillation: state-of-the-art review. Eur Heart J Cardiovasc Imaging. 2014;15:1-5.

17. Lacalzada-Almeida J, García-Niebla J, Bayés-de LA. Speckle-tracking echocardiography and advanced interatrial block. Rev Esp Cardiol. 2017;70:591. 
18. Montserrat S, Gabrielli L, Bijnens B, et al. Left atrial deformation predicts success of first and second percutaneous atrial fibrillation ablation. Heart Rhythm. 2015;12:11-8.

19. Benito EM, De Luna AB, Baranchuk A, Mont L. Extensive atrial fibrosis assessed by late gadolinium enhancement cardiovascular magnetic resonance associated with advanced interatrial block electrocardiogram pattern. Europace. 2017;19:377.

20. Martínez-Sellés M, Fernández Lozano I, Baranchuk A, et al. Should we anticoagulate patients at high risk of atrial fibrillation? Rev Esp Cardiol. 2016;69:374-6.

21. Bayés de Luna A, Baranchuk A, Martínez-Sellés $M$, et al. Anticoagulation in patients at high risk of stroke without documented atrial fibrillation. Time for a paradigm shift? Ann Noninvasive Electrocardiol. 2017;22(1). doi:10.1111/anec.12417.

22. Friberg $L$, Rosenqvist M, Lip GY. Net clinical benefit of warfarin in patients with atrial fibrillation: a report from the Swedish atrial fibrillation cohort study. Circulation. 2012;125:2298-307.

23. Martínez-Sellés $M$, Baranchuk $A$, Elosua $R$, de Luna AB. Rationale and design of the BAYES (interatrial block and yearly EventS) registry. Clin Cardiol. 2017; 40:196-9.

24. Vicent L, Martínez-Sellés M. Electrocardiogeriatrics: ECG in advanced age. J Electrocardiol. 2017; doi:10.1016/j.jelectrocard.2017.06.003.

25. Kumarathurai P, Mouridsen MR, Mattsson N, Larsen BS, Nielsen OW, Gerds TA, Sajadieh A. Atrial ectopy and N-terminal pro-B-type natriuretic peptide as predictors of atrial fibrillation: a population-based cohort study. Europace. 2017 Mar 1;19:364-70.

26. Khatib R, Joseph P, Briel M, Yusuf S, Healey J. Blockade of the renin-angiotensinaldosterone system (RAAS) for primary prevention of non-valvular atrial fibrillation: a systematic review and meta analysis of randomized controlled trials. Int J Cardiol. 2013;165:17-24.

27. Zhang L, Zhang N, Tang X, Liu F, Luo S, Xiao H. Increased a-actinin-2 expression in the atrial myocardium of patients with atrial fibrillation related to rheumatic heart disease. Cardiology. 2016;135:151-9.

\section{Submit your next manuscript to BioMed Central and we will help you at every step:}

- We accept pre-submission inquiries

- Our selector tool helps you to find the most relevant journal

- We provide round the clock customer support

- Convenient online submission

- Thorough peer review

- Inclusion in PubMed and all major indexing services

- Maximum visibility for your research

Submit your manuscript at www.biomedcentral.com/submit

) Biomed Central 